\title{
Electrification of precipitating systems over the Amazon: Physical processes of thunderstorm development
}

\section{Rachel I. Albrecht}

Departamento de Ciências Atmosféricas, Universidade de São Paulo,

São Paulo, Brazil

Now at Divisão de Satélites e Sistemas Ambientais, Instituto Nacional de Pesquisas Espaciais, Cachoeira Paulista, Brazil

Carlos A. Morales and Maria A. F. Silva Dias

Departamento de Ciências Atmosféricas, Universidade de São Paulo, São Paulo, Brazil

\section{Abstract}

[1] This study investigated the physical processes involved in the development of thunderstorms over southwestern Amazon by hypothesizing causalities for the observed cloud-to-ground lightning variability and the local environmental characteristics. Southwestern Amazon experiences every year a large variety of environmental factors, such as the gradual increase in atmospheric moisture, extremely high pollution due to biomass burning, and intense deforestation, which directly affects cloud development by differential surface energy partition. In the end of the dry period it was observed higher percentages of positive cloud-to-ground (+CG) lightning due to a relative increase in $+\mathrm{CG}$ dominated thunderstorms (positive thunderstorms). Positive (negative) thunderstorms initiated preferentially over deforested (forest) areas with higher (lower) cloud base heights, shallower (deeper) warm cloud depths, and higher (lower) convective potential available energy. These features characterized the positive (negative) thunderstorms as deeper (relatively shallower) clouds, stronger (relatively weaker) updrafts with enhanced (decreased) mixed and cold vertically integrated liquid. No significant difference between thunderstorms (negative and positive) and nonthunderstorms were observed in terms of atmospheric pollution, once the atmosphere was overwhelmed by pollution leading to an updraft-limited regime. However, in the wet season both negative and positive thunderstorms occurred during periods of relatively higher aerosol concentration and differentiated size distributions, suggesting an aerosol-limited regime where cloud electrification could be dependent on the aerosol concentration to suppress the warm and enhance the ice phase. The suggested causalities are consistent with the invoked hypotheses, but they are not observed facts; they are just hypotheses based on plausible physical mechanisms.

Received 14 July 2010; revised 14 January 2011; accepted 21 January 2011; published 23 April 2011.

Keywords: lightning, deforestation, aerosol effect, cloud electrification.

Index Terms: 3304 Atmospheric Processes: Atmospheric electricity; 3324 Atmospheric Processes: Lightning; 3314 Atmospheric Processes: Convective processes; 3311 Atmospheric Processes: Clouds and aerosols; 3322 Atmospheric Processes: Land/atmosphere interactions $(1218,1631,1843,4301)$.

\section{Introduction}


Figure 1. (a) Topography and (b) vegetation map over the DRYTOWET field experiment. The instrumentation location is also given: radiosonde stations (circles), lightning detection sensors (triangles), and the weather radar (cross and open circle representing its $150 \mathrm{~km}$ range).

[2] Due to its vast area, the temporal and spatial variabilities of Amazonian cloud cover and rainfall are very heterogeneous and the precipitation is modulated by intraannual and intraseasonal oscillations. During the monsoon period (December-March) in southwestern Amazon (see location in Figure 1), convective systems are modulated by the predominant zonal wind direction [Petersen and Rutledge, 2001; Rickenbach et al., 2002], whereas before the monsoon season establishment (the transition between the dry and wet seasons, September-November) extreme continental conditions are observed, with convective systems of deep vertical development [Morales et al., 2004], corresponding to the period of greatest lightning activity in the clouds [Williams et al., 2002].

[3] The seasonal rainfall variability also regulates the agriculture and livestock management in some regions of the Amazon, where the deforested areas are occupied by seasonal crops and pasture. During the transition between the dry and wet seasons, local farmers prepare the land by setting fire to pasture areas. These fires outbreaks release large amounts of aerosols into the atmosphere [Artaxo et al., 2002], contributing considerably to the increase in the number of cloud condensation nuclei (CCN). Higher CCN concentrations have been suggested to modulate the convection development in various parts of the world. The so-called aerosol effect has two components, the direct and indirect effects [Rosenfeld and Lensky, 1998; Rosenfeld, 1999; Williams et al., 2002]. In the direct effect, aerosols scatter and absorb sunlight thus modifying the environment thermodynamics where clouds are developed, such as reducing the surface sensible heat flux at surface and increasing planetary albedo. In the indirect effect, a large number of CCNs can suppress the cloud warm phase of precipitation by increasing the number and decreasing the size of the cloud droplets, therefore enabling the cloud to reach the cold phase (where cloud electrification occur) and increasing cloud lifetime.

[4] The impact of deforestation on cloud cover and rainfall is dependent of the spatial scale of the deforestation [Baidya Roy, 2009]. Several studies based on global circulation models predict a strong reduction on precipitation with increased deforestation [Nobre et al., 1991; Costa and Foley, 2000; Werth and Avissar, 2002] (among others), while mesoscale models and observations report an increase in cloud cover and rainfall with the ongoing deforestation [Negri et al., 2004; Chagnon and Bras, 2005; Baidya Roy, 2009; Wang et al., 2009]. Moreover, mesoscale models show that orographic clouds forced by terrain over regions with lowland deforestation and associated increases (decreases) in the Bowen ratio lead to the elevation (lowering) of their cloud base heights [Ray et al., 2006]. This scenario conduces to changes in the direct harvesting of cloud water by montane vegetation [Pielke et al., 2006].

[5] As briefly discussed, wind regimes, seasons, topography, deforestation and atmospheric pollution are identified as potential modulators of convective systems characteristics and electrification in the Amazon. However, it is still not known what is the role of these processes on modifying the electrical structure and development of thunderstorms, i.e., what are their relative importance? As several important processes are involved, it is highly foreseeable that an interaction between them should determine the development of a thunderstorm, instead of only an isolated phenomenon. Actually, it is important to analyze the control conditions of where thunderstorms were developed. The large-scale together with the local environmental characteristics (such as vegetation cover and topography) drive the basic conditions for cloud systems and thunderstorm development. For example, during the dry season (July-September) the southwestern Amazon experiences large-scale subsidence, scarce low-level humidity and thermodynamically stable atmosphere, and these conditions are not favorable for deep convective development. As the wet season approaches (September-October), the atmospheric humidity increases giving convective systems their main ingredient (water vapor) and change the thermodynamics of the atmosphere to a conditionally unstable state. In this case, regions with propitious land cover and topography that are able to overcome the low-level stability are more likely to develop deep convective systems and therefore thunderstorms. When the wet season is fully established (November-March) water vapor is fully available and the environment thermodynamics is mainly unstable and favorable for deep convection. In this later case, local land cover and topography might play a less important role. 
[6] Knowing and considering the characteristics of the Amazon atmospheric dynamics avoid naïve conclusions when comparing thunderstorms that were developed in completely different control conditions. Therefore, the objective of this work is to attempt to identify and quantify the importance of each of these effects in the convective systems electrification over the Amazon during the transition between the dry and wet seasons (September-November). This work used a combination of cloud-to-ground lightning data in the state of Rondonia, Brazil (southwest Amazon), and data collected during an intensive field experiment during the transition between dry and wet seasons. Section 2 gives an overview of southwestern Amazon recent studies on the interaction between deforestation, biomass burning and precipitation systems, beyond cloud electrification and recent observations on cloud to ground lightning polarity. Section 3 describes the data and methodology used in this work, focusing on lightning data collected over Rondonia from 2000 to 2004, as well as the Large-Scale Biosphere Atmosphere (LBA) field experiment, that took place in this same region in 2002. Sections 4 and 5 present the results on Rondonia lightning annual cycle and cloud electrification characteristics by analyzing the correlations between several environmental variables, lightning and radar precipitation. Section 6 summarizes the findings of this study and offers speculations and hypothesis on the causality of the correlations found, based on previous observations presented in the literature. Section 7 presents our final remarks and suggests a "big picture" for the southwestern Amazon lightning activity and thunderstorm development.

\section{From the Large-Scale Circulation to the Microphysics and Electrification of Clouds Over the Amazon}

[7] The precipitation regime in the Amazon region is modulated by dynamic systems of microscales, mesoscales, and large scales. The period of rain and strong convective activity in most of the Amazon happens from November through March while the dry period and low convective activity occur between May and September [Figueiroa and Nobre, 1990]. The rainy season is characterized by a monsoon period, coupled with penetrating stationary frontal systems from middle latitudes that organize the local convection over southwest Amazon defining the (South Atlantic Convergence Zone) SACZ. During the monsoon active phase, the wind regime is predominantly westerly and the precipitating systems present more stratiform characteristics, while during the monsoon inactive phase (or break periods) the wind regime is predominantly easterly with enhanced convective characteristics and lightning activity [Petersen and Rutledge, 2001; Rickenbach et al., 2002; Carvalho et al., 2002].

[8] Despite decades of studies on the Amazon precipitation regime, the study of the precipitating systems' electrification in the region is recent, with its main contributions from intensive data collection campaigns, such as the field experiments WETAMC (Wet season Atmospheric Mesoscale Campaign [Silva Dias et al., 2002], conducted alongside the NASA TRMM-LBA campaign) and DRYTOWET-AMC (Dry-to-Wet Season-Atmospheric Mesoscale Campaign [Silva Dias et al., 2005]). The latter experiment was conducted in coordination with the field experiment LBA-SMOCC (Smoke Aerosols, Clouds, Rainfall and Climate) [Andreae et al., 2004]. One of the findings from the LBA research is that the Amazon has precipitating systems with oceanic characteristics during the wet season (low CCN concentration and a large amount of precipitation together with low electrical activity [Petersen and Rutledge, 2001; Williams et al., 2002]), and with continental characteristics during the transition between dry and wet seasons (high CCN concentration and precipitating systems associated with high electrical activity [Williams et al., 2002]).

[9] The role of enhanced aerosol concentration from biomass burning (and thereby CCN, as this type of particle are found to be good CCNs [Reid et al., 1998]) in thunderstorm electrification was proposed by Rosenfeld [1999] and Williams et al. [2002]: When a cloud is initiated in a clean planetary boundary layer (low CCN concentration-green-ocean regime), a small number of large droplets is formed due to more water vapor availability and the small number of particles. The activation of collision-coalescence and cloud precipitation processes prevail in the cloud warm phase $\left(\mathrm{T} \geq 0^{\circ} \mathrm{C}\right)$, reducing or not even developing the mixed and cold phases $\left(\mathrm{T}<0^{\circ} \mathrm{C}\right)$ of the cloud. As a result, the cloud electrification is compromised since it is dependent on the presence of large amounts of ice [Jayaratne et al., 1983; Takahashi, 1978]. However, in the case of a cloud initiated in a polluted planetary boundary layer (high CCN concentration-continental regime), a higher number of small droplets are formed due to the low water vapor availability for a higher number of particles. Therefore cloud droplets growth predominantly by water vapor condensation/diffusion, thus suppressing the collision-coalescence and warm precipitation processes. This fact allows larger liquid water quantities to ascend into the region of mixed and cold phases $\left(-20^{\circ} \mathrm{C}<\mathrm{T}<0^{\circ} \mathrm{C}\right)$, where they can contribute to the growth of high-density ice particles (like hail) and catalyze the noninductive electrical charge transfer process by collisions between ice particles [Takahashi, 1978; Saunders et al., 1991]. 
[10] Fernandes et al. [2006] attributed the increase of peak current magnitudes and the percentage of positive cloud-to-ground lightning (+CGs) during the period of heavy biomass burning in Rondonia as a consequence of enhancement of cloud droplets due to the high atmospheric loading of aerosols. The relationship between lightning polarity and biomass burning was also studied by Lyons et al. [1998], Murray et al. [2000], and Smith et al. [2003] during the 1998 Mexican forest fires. Lyons et al. [1998] found that the percentage of +CGs was three times higher than the climatological mean. Murray et al. [2000] emphasized that this enhancement was in isolated points, and only where the biomass burning plumes inserted a high quantity of aerosols in the atmosphere. In essence, the enhanced $+\mathrm{CGs}$ could be explained by the positive charging gained by graupel in the mixed regions with high LWC. According to laboratory studies, graupel is mainly positively charged at all temperature ranges under high LWC conditions, although some laboratory results have found that limited or no charging can occur in extremely high liquid water content regimes [Takahashi, 1978; Saunders and Peck, 1998; Pereyra et al., 2000; Saunders et al., 2004].

[11] Besides the apparent effect of intensifying thunderstorms electrification and increasing the number of + CGs by enhancing the aerosol concentration in the lower troposphere pointed out above, those results were inconclusive when also investigating the role of thermodynamic control on vertical convective structure and lightning production [Halverson et al., 2002; Williams et al., 2002; Smith et al., 2003]. For the WETAMC field campaign, Halverson et al. [2002] and Williams et al. [2002] found that convective systems and enhanced lightning activity during the easterlies developed over an environment with larger convective available potential energy (CAPE), a drier lower to midlevel layer, and a stronger and deeper wind shear layer. These findings emphasize the role of environmental thermodynamics in the evolution of thunderstorms and rainfall during the distinct wet season wind regimes, revealing distinct convective vertical structure and cloud-to-ground (CG) lightning flash rate density between the two wind regimes [Cifelli et al., 2002, 2004]. Cifelli et al. [2002, 2004] demonstrated that the easterly (westerly) regime exhibited stronger (weaker) updrafts and deeper (shallower) radar reflectivity cores above the melting level, resulting in large (reduced) lightning activity. Cifelli et al. [2004] also showed that, above the boundary layer, the active phase of the monsoon is characterized by a greater virtual temperature excess for near-surface rising parcels. Furthermore, Smith et al. [2003] pointed out that during the 1998 Mexican fires the lower atmosphere was anomalously drier and hotter which also resulted in anomalously increased CAPE.

[12] More recently, Carey and Buffalo [2007] showed that the mesoscale thermodynamics of the environment can indirectly control the CGs polarity due to changes on the structure, dynamics and microphysical properties of severe storms. These authors showed that positive storms (storms with more than $25 \%$ of $+\mathrm{CGs)}$ tend to develop in environments with drier low to medium troposphere, higher cloud base heights $(\mathrm{CBH})$, less thick warm cloud depth $\left(\mathrm{WCD}=\mathrm{height}\right.$ of $0^{\circ} \mathrm{C}$ isotherm minus cloud base height), greater conditional instability, stronger wind shear between 0 and $3 \mathrm{~km}$, and greater buoyancy in the storm mixed phase. The CBH and the related WCD were the more differentiated parameters between positive (higher CBH and smaller WCD) and negative (lower CBH and larger WCD) storms, giving thoughts to the "warm cloud depth hypothesis": higher CBH and consequent smaller WCDs can be interpreted as regions of wider updrafts with less entrainment, resulting in less dilution of cloud water and buoyancy in positive storms. In this scenario CAPE can be better processed, intensifying updrafts and suppressing warm precipitation, which results in higher liquid water content in the mixed phase region, a key component for positively charge graupel during collisions with small ice particles [Takahashi, 1978; Saunders and Peck, 1998; Pereyra et al., 2000; Saunders et al., 2004]. Positive graupel leads to inverted polarity thunderstorms, which produce predominantly +CGs. Furthermore, larger mixed phase water contents can produce hail of larger sizes, a storm element often observed on $+\mathrm{CG}$ dominated storms [Carey and Rutledge, 1998].

[13] One interesting work that related lightning polarity to both the enhanced aerosol concentrations and environment thermodynamics during forest fires in Colorado was conducted by Lang and Rutledge [2006]. These authors compared the forest fire event to the climatology of CGs and aerosol optical depth (AOD), finding an increase in the percentage of + CGs that was more than double from the climatology over Colorado during the enhanced periods of increased AOD caused by the fires. However, when investigating the deviations of thermodynamic variables from the climatology, they have also found signs of higher $\mathrm{CBH}$, shallower WCD and larger $\mathrm{CAPE}$ as those of Carey and Buffalo [2007] with more relevance to the high LWC hypothesis for +CGs.

[14] When scenarios of enhanced aerosol are simulated by cloud resolving models, mixed results are found [Khain et al., 2005; Seifert and Beheng, 2005; van den Heever et al., 2006; van den Heever and Cotton, 2007; Carrio et al., 2010; Ward et al., 2010] (among others). For example, Khain et al. [2005] found that smokeenhanced CCN concentrations produced smaller cloud droplets, reducing the production of drizzle drops that when frozen the associated latent heat release resulted in 
more vigorous convection. On the other hand, Seifert and Beheng [2005] showed that the effect of changes in CCN on mixed phase convective clouds is dependent on cloud type: for small convective storms, an increase in $\mathrm{CCN}$ decreased both precipitation and the maximum updrafts, while for multicellular storms it increased maximum updrafts and total precipitation. Moreover, van den Heever et al. [2006] and van den Heever and Cotton [2007] found complex nonlinear feedbacks between the changes in microphysics and storm dynamics, which in the case of deep convective clouds the effect of changes in cloud aerosol loading is nearly impossible to predict [Cotton and van den Heever, 2006]. The only concrete result is that the most important pathway for feedbacks from microphysics to dynamics is via the release of latent heat of freezing [Seifert and Beheng, 2005].

[15] More recently Carrio et al. [2010] and Ward et al. [2010] found that the size of the activated droplets had an important effect in the mixed phase of the clouds. In these authors' cloud simulations, very polluted environments would activate a larger number of smaller droplets that do not grow effectively and suppress the collisioncoalescence process. This lead to higher LWC in the mixed phase but with smaller supercooled droplets that made the rimming growth of ice particles to become very inefficient, producing ice particles reduced in number and size. This scenario would also reduce the electrification of the clouds and lightning production.

\section{Data and Methodology}

[16] In order to identify and quantify the role of the aerosols, thermodynamics, large-scale, topography and vegetation on the cloud electrification over the state of Rondonia, Brazil (southwest Amazon, Figure 1), this study gathered a comprehensive 5 year cloud to ground (CG) lightning database and measurements from the DRYTOWET field campaign that took place in Rondonia, Brazil, during the year of 2002. As a consequence, the results are divided into two main parts: (1) a study of the temporal and spatial distribution of CGs over the 5 year data, and (2) a study of the convective systems during the DRYTOWET field campaign. Figure 1 shows the study area and the main position of the instrumentation as well as the topography (TOPEX satellite [Smith and Sandwell, 1997]) and vegetation map (LANDSAT satellite [Instituto Nacional de Pesquisas Espaciais (INPE), 2008]).

\subsection{Lightning Data}

[17] The lightning data used in this study is from the Rondonia Lightning Detection Network (RLDN), which was deployed in the state of Rondonia in 1999 as part of the TRMM (Tropical Rainfall Measuring Mission) satellite Ground-Validation program [Blakeslee et al., 2003]. This network is composed of four ALDF (Advanced Lightning Direction Finder) sensors, with a long base and high-gain configuration, ensuring a flash detection efficiency greater than $90 \%$ over Rondonia using four sensors and greater than $70 \%$ using three sensors [Rompala and Blakeslee, 2008]. These sensors measure the location, peak current and polarity of CGs flashes using the combined Magnetic-Direction-Finder and time-of-arrival techniques. These sensors are located in Vilhena $\left(60.10^{\circ} \mathrm{W}, 12.79^{\circ} \mathrm{S}, 614 \mathrm{~m}\right), \mathrm{Ouro}^{\circ}$ Preto d'Oeste $\left(62.24^{\circ} \mathrm{W}\right.$, $\left.10.73^{\circ} \mathrm{S}, 245 \mathrm{~m}\right)$, Machadinho d'Oeste $\left(62.02^{\circ} \mathrm{W}, 9.40^{\circ} \mathrm{S}, 132 \mathrm{~m}\right)$ and Guajara-Mirim $\left(65.28^{\circ} \mathrm{W}, 10.79^{\circ} \mathrm{S}, 155 \mathrm{~m}\right)$, as shown in Figure 1.

[18] For this study, the CG flashes have been filtered according to Cummins et al. [1998] suggestion, i.e., the minimum peak current of $10 \mathrm{kA}$ is applied to prevent data contamination by intracloud (IC) discharges. The recent research of Biagi et al. [2007] showed that "there is no unique threshold for classifying a small-positive report as a CG stroke, but an averaged estimated peak current of $15 \mathrm{kA}$ appears to be the value where the number of false CG reports equals the number of correct reports." As many research in the literature adopted the $10 \mathrm{kA}$ of Cummins et al. [1998] threshold, we decided for continuing to follow these authors' lead and be able to compare our results with previous works. However, when comparing the percentage of + CGs derived with and without this threshold (not shown) no significant differences were found. Also no detection efficiency correction was applied to the networks' detections once the main focus of our work was over the $150 \mathrm{~km}$ radar coverage, which is in the middle of the RLDN (Figure 1a).

\subsection{The DRYTOWET Field Campaign}




\subsubsection{The Weather Radar}

[19] During this field experiment a Brazilian S band (2.7 GHz) weather radar (manufactured by TECTELCOM) was installed in Rondonia $\left(62.42^{\circ} \mathrm{W}, 10.9^{\circ} \mathrm{S}, 433 \mathrm{~m}\right)$ measuring convective systems from 16 September to 7 November 2002, using 24 elevations with a time interval of 15 (16-23 September) to 10 (23 September to 7 November) minutes. Data quality control was performed by STORM-T laboratory (http://www.storm-t.iag.usp.br/) and converted into CAPPIs (Constant Altitude Plan Position Indicator) that have $2 \times 2 \mathrm{~km}$ horizontal and $1 \mathrm{~km}$ vertical resolution, from $2 \mathrm{~km}$ through $19 \mathrm{~km}$ height [Morales et al., 2004]. Moreover, the vertically integrated liquid (VIL, $\mathrm{kgm}^{-2}$ ) water content given by Amburn and Wolf [1997] as computed for each radar CAPPI as following:

$$
\begin{aligned}
V I L & =\sum_{h=h_{0}}^{20 \mathrm{~km}} L W C_{h} \Delta h, \\
W C_{h} & =3.4 \times 10^{-3}\left(10^{\left(\mathrm{Z}_{h} / 10\right)}\right)^{(4 / 7)}
\end{aligned}
$$

where $L W C_{h}$ and $Z_{h}$ are the liquid water content $\left(\mathrm{kg} \mathrm{m}^{-3}\right)$ and the radar reflectivity factor (dBZ) at height level $h(\mathrm{~km})$, respectively, $\Delta h$ is the height resolution $(1 \mathrm{~km})$ and $h_{0}$ is the start point of the integration. We defined $h_{0}=2 \mathrm{~km}$ to calculate VIL over the entire vertical column of the precipitating system (hereafter called "total VIL") and $h_{0}=5 \mathrm{~km}$ to calculate VIL over the zone of electrical charging, i.e., in the presence of frozen hydrometeors (hereafter called "mixed+cold VIL").

[20] All precipitating systems that passed within $150 \mathrm{~km}$ of the radar coverage area (Figure 1) were tracked by the Forecast and Tracking the Evolution of Cloud Cluster (ForTraCC) algorithm [Machado et al., 2002; Vila, 2004; Vila et al., 2008]. As described by Vila et al. [2008], the main steps of the ForTraCC are a cloud cluster detection method based on size and temperature thresholds, a statistical module to identify morphological and radiative parameters of each mesoscale convective system (MCS), a tracking technique based on MCS overlapping areas between successive images, and a forecast module based on MCS evolution in previous time steps. In our case, instead of using brightness temperature from satellite images we have adapted the algorithm for radar reflectivity at $3 \mathrm{~km}$ CAPPI height using a $20 \mathrm{dBZ}$ threshold, which permitted us to track not only MCS but also local convection. The choice of CAPPI at $3 \mathrm{~km}$ was made based on the scan strategy of the radar. This radar had a $1.8^{\circ}$ beam width which determined that lower heights of CAPPI (i.e., 2 or $1 \mathrm{~km}$ ) were "filled" only by a limited number of elevations at distances as far as $150 \mathrm{~km}$. Moreover, the cloud base heights over the Amazon are known to be lower than $3 \mathrm{~km}$ of height, but not always lower than $2 \mathrm{~km}$ [Fisch et al., 2004], therefore CAPPI at $3 \mathrm{~km}$ guarantees the detection and tracking of any convective system regardless its depth.

[21] Among the steps outlined above, the main one is the determination of "family" of clusters based on the radar reflectivity and size thresholds. At this stage, the algorithm monitors the clusters from its inception until its dissipation, taking into account all the mergers and divisions suffered by them throughout their life cycle. Also we considered only the systems which had spontaneous initiation and dissipation within the radar area, that is, both in the initiation and dissipation there was no interaction (merge) with other system nor the separation of the identified system. This criterion was the same followed by Vila [2004] to obtain a more homogenous set of information to study the characteristics of MCS. However, mergers and separations during the life cycle of a particular system were permitted since otherwise the data set would be very limited.

[22] The CG lightning detected by the RLDN was also tracked together with the systems detected by ForTraCC, being accumulated during the time period of each radar volume scan. Finally, the life cycle of all storms detected and tracked by the ForTraCC were normalized into a scale from 0 to 1 , where 0 represents the beginning and 1 the end of the storm. The normalized lifecycle time $\left(t_{\text {norm }}\right)$ produces a way to compare storms of different sizes and timescales on the same life cycle stage, i.e., initiation $(0-0.3)$, maturation $(0.3-0.7)$ and dissipation $(0.7-1.0)$. We have also determined the place of initiation of each system by extrapolating their positions 30 min previous to their appearance on the radar field. This extrapolation was calculated by displacing the cluster according to its mean first 30 min velocity on the radar. The 30 min corresponds to the typical time required for cloud droplets to grow to sizes detectable by weather radars [Pruppacher and Klett, 1997; Rogers and Yau, 1989]. 
[23] In order to obtain large-scale conditions over all state of Rondonia and not only isolated points, reanalysis data from B. Biazeto and M. A. F. Silva Dias (Analysis of the impact of rainfall assimilation during LBA atmospheric mesoscale campaigns in southwest Amazon, submitted to Atmospheric Research, 2010) were used. This higher-resolution reanalysis $(20 \times 20 \mathrm{~km}$ horizontal resolution) was generated with the Brazilian Regional Atmospheric Modeling System (BRAMS) that performed a three months run assimilating precipitation from TRMM satellite (every $3 \mathrm{~h}$ ), soil humidity (once a day [Gevaerd et al., 2006; Gevaerd and Freitas, 2006]) and radiosonde temperature and humidity profiles. A network of radiosonde stations (Figure 1) performed vertical soundings every $3 \mathrm{~h}$ from 0000 through $2100 \mathrm{UTC}$. As a result, Biazeto and Silva Dias (submitted manuscript, 2010) improved the representativeness of variables like temperature, dew point temperature, relative humidity and precipitation compared to the observations. The greatest improvements where many times greater than $50 \%$ in comparison with the control simulations. Therefore, these reanalysis give more representative profiles of storms related environmental variables over all the state of Rondonia, such as the convective potential energy (CAPE), convective inhibition energy (CINE), cloud base height (CBH), and warm cloud depth (WCD). CAPE is defined as the positive tropospheric buoyancy layer, conditionally unstable, while CINE is the negative buoyancy layer, and they were calculated according to Doswell and Rasmussen [1994]. The height level where the CBH is located were inferred by the lifted condensation level (LCL), pressure $\left(P_{\mathrm{LCL}}\right)$ and temperature $\left(T_{\mathrm{LCL}}\right)$ according to Bolton [1980]. The WCD was calculated using the difference between the $0^{\circ} \mathrm{C}$ isotherm and the $\mathrm{CBH}$. These variables were correlated with convective systems detected by the radar and lightning activity.

\subsubsection{Aerosols and Biomass Burning}

[24] Aerosol size distributions were measured during DRYTOWET at Fazenda Nossa Senhora (Figure 1) by the Lund University group, through the Differential Mobility Particle Sizer (DMPS) sensor [Rissler et al., 2006]. These data were collected throughout the time of radar operation, with a 10 min temporal resolution, at the surface level. The aerosol diameter ranges are logarithmically staggered into 38 channels, covering sizes from 3 to $850 \mathrm{~nm}$. For more details about the instrument and data set the reader is referred to Rissler [2003] and Rissler et al. [2006]. Aerosol size distribution were analyzed during each storm event over the radar with respect to its electrification in order to investigate the biomass burning aerosol effect on thunderstorm electrification and CG polarity suggested by previous authors [Lyons et al., 1998; Murray et al., 2000; Smith et al., 2003; Fernandes et al., 2006]. For that, the aerosol size distribution measured by the DMPS for each 10 min interval was matched to the closest radar CAPPI in time. This distribution was then considered to be the pollution background of the entire domain of the radar, associating all precipitating clusters (tracked by the ForTraCC software) within the CAPPI to the time-matched aerosol size distribution. In the Amazon, the primary sources of aerosols are from forest biogenic emissions and biomass burning [Artaxo et al., 1998, 2002; Poschl et al., 2010]. Due to the vast area of the Amazon basin, aerosol size distribution might differ from place to place, but their transport throughout the basin can also homogenize the distribution [Artaxo et al., 1998, 2002], except under fire spots, where it has been reported huge concentrations of aerosols and the development of pyro-cumulus [Andreae et al., 2004]. Therefore this extrapolation of the punctual DMPS measurement to the entire domain of the radar coverage might not be ideal, but it is the best measurement of pollution available at this time.

\subsubsection{Topography and Vegetation}

[25] Topography data from TOPEX satellite [Smith and Sandwell, 1997] and vegetation data from LANDSAT [INPE, 2008] were also used in the analysis of thunderstorms' development. Topography was investigated as a parcel lifting mechanism and a higher source of heat, while different types of vegetation are related to the different sensible and latent heat partitions that are able to generate local circulations and change precipitation characteristics [Wang et al., 2000; Baidya Roy and Avissar, 2002; Negri et al., 2004; D'Almeida et al., 2007; Silva et al., 2008]. Rondonia topography and vegetation maps are illustrated in Figure 1, where the vegetation types are simplified as deforested areas (predominantly grass-pasture), forest, water (rivers), and others (composed by savanna with some occurrence of floodplains and massive rocks), corresponding to $55.2 \%, 33.8 \%, 0.8 \%$, and $10.2 \%$, respectively, of Rondonia state.

\subsubsection{Determination of the Dry to the Wet Seasons}


[26] Finally, the entire DRYTOWET data analysis has been based and divided according to the evolution of the wet season establishment. This division was based on vertical integrated water vapor carried out by Sapucci [2005] that employed Global Positioning System (GPS) receivers installed in Porto Velho, Fazenda Nossa Senhora and Guajara-Mirim during the DRYTOWET experiment. Considering the radar operation period, the storm analysis can be divided in accordance to the establishment of the wet season in Rondonia given by Sapucci [2005]: Dry period, 16 September to 4 October 2002 (19 days); Transition period, 5-19 October 2002 (15 days); Wet period, 20 October to 7 November 2002 (20 days).

[27] This division into Dry, Transition, and Wet periods makes possible comparisons between thunderstorms observed during the campaign being aware of the distinct control conditions imposed by the large-scale dynamics of the atmosphere discussed in sections 1 and 2.

\subsection{Statistical Significance}

[28] The statistical significance of the differences between some variables studied here (VIL, flash rate density, and aerosol size distributions) for positive, negative and nonthunderstorms were tested using the one-way Analysis of Variance (ANOVA) method [Maindonald and Braun, 2007]. Here we used the one-way ANOVA to test for differences among two independent groups, i.e., positive and negative thunderstorms, and thunderstorms and nonthunderstorms. As we performed only tests for two groups the ANOVA test is reduced to the $F$ test. The null hypothesis were stated as if the average of the groups studied are equal with a significance level of $95 \%$ (alpha $=$ 0.05). Before applying the test, the samples were checked for "normality" (check if the distributions of the residuals were normal) using the Anderson-Darling test also with a significance level of 95\% [D'Agostino and Stephens, 1986]. If the distributions failed the Anderson-Darling's test, the logarithm was applied to the data samples and then this test was applied again. Fortunately, the log samples had a normal distribution and the one-way ANOVA was then applied to these lognormalized samples. To conduct all the analysis in this paper we used the statistical software R [Ihaka and Gentleman, 1996].

\section{Temporal and Spatial Distribution of CGs Over Rondonia From 2000 to 2004}

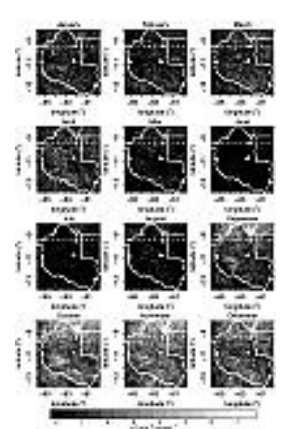

Figure 2. Mean monthly spatial distribution of CG flashes densities (-CGs and +CGs) detected by RLDN from 2000 to 2004 over Rondonia. The white triangles show the RLDN sensors, and the white dashed lines indicate the area above Machadinho d'Oeste sensor that is not used in further analysis.

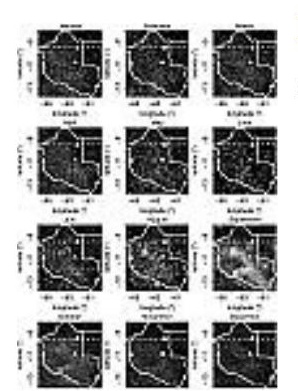

Figure 3. Mean monthly spatial distribution of the percentage of $+\mathrm{CG}$ detected by RLDN from 2000 to 2004 over Rondonia. The white triangles show the RLDN sensors, and the white dashed lines indicate the area above Machadinho d'Oeste sensor that is not used in further analysis. 
[29] The temporal and spatial distribution of the CG flashes over Rondonia during the period of 2000 and 2004 is presented in Figure 2. The high CG density north/northeast of Machadinho d'Oeste sensor $\left(62.02^{\circ} \mathrm{W}, 9.40^{\circ} \mathrm{S}\right)$ is related to erroneous solutions of the RLDN (R. Blakeslee, personal communication, 2010): those locations are mainly from two receivers solutions, Machadinho d'Oeste and Ouro Preto, so any bearing and TOA error will produce solutions along the baseline of the sensors, specially north of them. The region above Machadinho d'Oeste sensor (north of $9.40^{\circ} \mathrm{S}$, indicated by the dashed lines in Figure 2) was not considered in this analysis, as well as in Figure 3. It can be observed that CG density starts increasing in August with $1.0 \mathrm{~km}^{-2}$ month $^{-1}$ values spread over all state and maximums of 2.0 $\mathrm{km}^{-2}$ month $^{-1}$ at northeast Rondonia near the Amazonas state boundary. By September, the CG density increased over $2.0 \mathrm{~km}^{-2}$ month ${ }^{-1}$ in most part of Rondonia, and high densities were observed in two regions: (1) at the central west region, approximately near the more elevated areas (Figure 1); and once again (2) at northeast Rondonia near the Amazonas state boundary. During October, November and December the CG densities were higher than $3.0 \mathrm{~km}^{-2}$ month ${ }^{-1}$ all over Rondonia, reaching even higher values $\left(>5.0 \mathrm{~km}^{-2} \mathrm{month}^{-1}\right)$ again in the previous mentioned regions 1 and 2, but also over central south of the state, west of the high topography ( $\left.>350 \mathrm{~m}\right)$. Upon the establishment of the rainy season and the South American Monsoon [Zhou and Lau, 1998], the CG densities decreased in January and continued in February. Mainly from January to March convective systems over southwest Amazon are regulated by westerlies (monsoon) and easterlies (break periods) wind regimes associated to the presence and absence, respectively, of the SACZ [Petersen and Rutledge, 2001; Rickenbach et al., 2002], where the easterlies thunderstorms are responsible for the major part of CGs since they are more convectively intense than westerlies thunderstorms [Petersen and Rutledge, 2001; Cifelli et al., 2002; Williams et al., 2002]. In March and April there is an interesting enhancement of the CG lightning activity, and then it almost collapses from May through July when the dry season is completely established. During the transition between the wet to the dry season, the troposphere is relatively drier and the conditional instability and increased CAPE favor the development of thunderstorms. It is the same situation as the transition between the wet and the dry seasons (September-October), except that in May-July the available humidity is decreased and large-scale subsidence inhibits convection [Williams et al., 2002; Andreae et al., 2002].

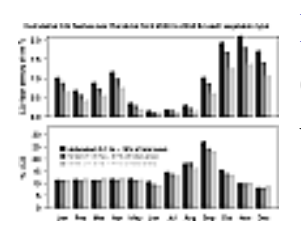

Figure 4. Cumulative monthly CG flash density and percentage of +CGs over different types of vegetation: deforested areas, forest, and others (water, savannas, and rocks). Numbers in parentheses correspond to the total area of each type of vegetation as well as its percentage from the whole studied area over Rondonia. Area north of Machadinho d'Oeste sensor was not considered.

[30] To identify the regions with high percentages of + CGs over Rondonia, Figure 3 shows the monthly spatial distribution of $+\mathrm{CG}$ percentage $(\%+\mathrm{CG})$ detected by RLDN from 2000 to 2004. It is noted that from June to September the $\%+$ CGs increased dramatically and it decreases after October. The most notable characteristic of this monthly distribution of $\%+C G s$ is the northwest-southeast orientation and the west branch of $\%+C G$ higher than $50 \%$ from August to October, especially in September. Comparing with the vegetation map in Figure 1, it is found that this region of $\%+C G>50 \%$ is coincident with the deforested area. To illustrate this correlation, Figure 4 shows the cumulative monthly CG flash density (that is, the total number of CGs over the entire area by month) and the $\%+C G s$ from 2000 to 2004 as a function of vegetation type. CG density is calculated by the total number of CGs in a particular type of vegetation and normalized by the total area of the same type of vegetation. It can be seen in Figure 4 that the CGs density was similar among all types of vegetation from January to August. In September and October the difference between CGs density over deforested areas and other types of vegetation increased $\left(\sim 0.24 \mathrm{CG} \mathrm{km}^{-2}\right)$ and in November this difference reached its peak $\left(0.59 \mathrm{CG} \mathrm{km}{ }^{-2}\right)$. The difference in CG density between forested and deforested vegetation was less than $0.09 \mathrm{CG} \mathrm{km}^{-2}$ from January to August, and then increasing to $\sim 0.23$ in September and November. Therefore, even with the deforestation representing only $18 \%$ of the area (5.1 ha), cloud-to-ground lightning are more likely to occur over these areas during months of high electrical activity (September-November, Figures 2 and 3). These results indicate that deep convection has higher probability of occurrence in 

of deforestation.

[31] It is a fact that deforestation causes a variation in the energy partition, i.e., sensible (H) and latent (LE) heats. For instance, replacing forest by pasture, the evapotranspiration (LE) is reduced while $\mathrm{H}$ is increased. Furthermore, taking into account the relatively drier lower troposphere observed in September, clouds are initiated preferentially over warmer and drier surfaces like pasture [Rabin et al., 1990]. The increase in sensible heat generates more intense turbulent transients over deforested areas, making the planetary boundary layer (PBL) higher over pasture than over forest [Fisch et al., 2004] in the dry season. Therefore, the PBL mixed layer in the forest is more dense and shallower than in the pasture, thus generating a density gradient. This density gradient, in turn, produces a horizontal gradient of pressure between these two areas which, in response, triggers a mesoscale circulation [Baidya Roy and Avissar, 2002; Souza et al., 2000].

[32] In spite of the higher $\%+C G s$ occurrence over the deforested areas during August-October, the topography over Rondonia (Figure 1) also has high elevated regions oriented northwest-southeast, creating a valley that is located on the eastern side of areas with more than $50 \%$ of + CG. Topography can also be an external lifting mechanism for air parcels that can balance the stability of the dry atmosphere and initiate convection. Ray et al. [2006] showed that deforested areas over regions of low terrain and the associated increase (decrease) in the Bowen ratio cause the elevation (lowering) of the orographic clouds forced by terrain downwind.

[33] Therefore, it is plausible to conclude that electrical activity in southwestern Amazon is initiated in the transition between the dry to the wet seasons (SeptemberOctober) reaching its maximum when the wet season is established (November). This transition of seasons are also coupled with the period that the local farmers set fire in their pasture in order to prepare the soil for agriculture and livestock, causing a tremendous increase in atmospheric pollution [Artaxo et al., 1998] that is coincident with the increase in $+\mathrm{CG}$ percentage.

[34] Due to the superposition of the several possible causes of thunderstorm electrification such as atmospheric (pollution) loading, topography, different surface energy partition effects due to deforestation, there is a need of a more detailed analysis, which is presented in section 5.

\section{DRYTOWET Convective Systems and Their Environmental Variables}

[35] In order to understand how the convective systems become electrically active during their development, the precipitation systems observed in the radar area have been tracked during their complete lifecycle and the CG flashes have been used to identify whether each cluster is a thunderstorm or not. Moreover, for each cluster tracked the atmospheric variables (as described in section 3) from the reanalysis have been incorporated. In sections 5.1-5.4 the precipitating storms are analyzed in respect to the vertical radar reflectivity structure and lightning activity, followed by the influence of topography, vegetation, thermodynamics and aerosol effects on the thunderstorm initiation and development. All analyses follow the dry, transition, and wet season classification of Sapucci [2005] described in section 3.2.5.

\subsection{Characteristics of Thunderstorms}


[36] As already presented in section 4, lightning activity starts in September and ends in April. In respect to the thunderstorms that developed over the radar area (150 $\mathrm{km}$ of radius), Figure 5 shows the spatial distribution of total CG densities (positive and negative polarities) and \%+CG detected by the RLDN during the Dry, Transition, and Wet periods sampled during the DRYTOWET field campaign. Following the 5 year average shown in section 4, CG density increased from the Dry to the Wet periods with maximums of $1.75 \mathrm{CG} \mathrm{km}^{-2}$ during the Transition period at the north and central northwest-southeast of Rondonia. The $\%+C G$ presented higher values during the Dry period, and as the wet season was established it decreased. As in the 5 year average (Figure 3, September), the Dry period showed regions with predominance of + CGs $(>50 \%)$ in a north northwest-southeast orientation and a west branch, mapping the deforested areas of Rondonia (Figure 1b).

[37] From 16 September 2002 to 7 November 2002 a total of 5,329 raining clusters crossed the TECTELCOM radar within the 150 km coverage. Table 1 shows the distribution of these precipitating systems as a function of their electrification status, lifetime duration and period of the experiment. About 76-82\% of the raining clusters detected by the radar during Dry, Transition, and Wet periods did not present any cloud-to-ground lightning during their entire lifecycle, and are called nonthunderstorms hereafter. Since the RLDN detects only cloud-to-ground lightning, electrified clouds that produced only intracloud lightning could be considered as nonthunderstorms. Moreover, the cloud cluster and CG tracking were done by the CAPPI $3 \mathrm{~km}$ height, therefore discharges that happened outside the $20 \mathrm{dBZ}$ cluster area were not considered. The remaining systems that were observed CG flashes during their lifecycle are called thunderstorms and were divided according to their lifetime duration: $<30,30-60,60-120,>120 \mathrm{~min}$, as described in section 3 . Approximately $33 \%$ of the detected thunderstorms had lifetime duration of less than 30 min on all analyzed period, while $59 \%$ of them had lifetime duration between 30 and $120 \mathrm{~min}$, and only $8 \%$ of them lasted more than $2 \mathrm{~h}$. In order to understand the role of electrification process, only the thunderstorms that had lifetime duration longer than $30 \mathrm{~min}$ are analyzed.

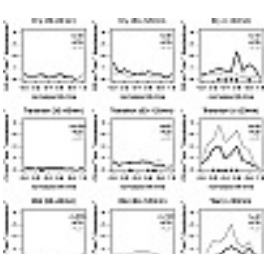

Figure 6. Mean frequency of $+\mathrm{CG}$ and $-\mathrm{CG}$ flashes during the normalized life cycle of thunderstorms for Dry, Transition, and Wet periods, divided into total lifetime categories $(30-60,60-120,>120 \mathrm{~min})$. The indicated numbers in the plots correspond to the number of cases for that particular category lifetime category (positive + negative thunderstorms). The stars represent the samples that were statistically significant at the $95 \%$ significance level performed for each $t_{\text {norm }}$ comparing the variances between the + CGs and - CGs flash rate density per thunderstorm.

[38] Figure 6 summarizes the lightning activity (positive and negative CG flashes) for all the thunderstorms (Table 1) that lasted more than 30 min, according to its lifetime class (30-60, 60-120 and >120 min) and period (Dry, Transition, and Wet). The life cycle of the radar storms were normalized into a scale from 0 to 1 , as described in section 3.2.1. It can be observed in Figure 6 that during the Dry period, all thunderstorms presented a higher mean frequency of $+\mathrm{CG}$ than $-\mathrm{CG}$ over their entire duration, except for thunderstorms that last 60-120 min at their maturate stage $\left(t_{\text {norm }}=0.5\right)$. Thunderstorms with maximum duration between 30 and 120 min produced mean flashes rates of $0.1-1.0 \mathrm{CG} \mathrm{km}^{-2} \mathrm{~min}^{-1}$ thunderstorm ${ }^{-1}$ over all their lifetime, both for positive and negative polarities. Dry period thunderstorms with duration longer than 120 min showed a mean peak of $2.4 \mathrm{CG} \mathrm{km}^{-2} \mathrm{~min}^{-1}$ thunderstorm ${ }^{-1}$ for $+\mathrm{CG}$ at the mature stage $\left(t_{\text {norm }}=0.6\right)$ and $1.3 \mathrm{CG} \mathrm{km}^{-2} \mathrm{~min}^{-1}$ thunderstorm $^{-1}$ 
during the dissipation stage $\left(t_{n o r m}=0.8\right)$. The statistical significance of these results show that $+\mathrm{CG}$ and $-\mathrm{CG}$ flash rate densities are significantly different at $95 \%$ level for most of the thunderstorms life cycle $\left(0.3 \leq t_{\text {norm }} \leq 0.8\right)$ that lived longer than 120 min, while they were not significant for both 30-60 and $60-120$ min lived thunderstorms.

[39] During the Transition and Wet periods, the $-\mathrm{CG}$ frequency was higher for all thunderstorms (Figure 6). Thunderstorms with a lifetime greater than $1 \mathrm{~h}$ produced 0.1 to $1.0 \mathrm{CG} \mathrm{km}^{-2} \mathrm{~min}^{-1}$ thunderstorm ${ }^{-1}$ over their entire life cycle of both flash polarities. Thunderstorms that lasted over $2 \mathrm{~h}$ showed a $-\mathrm{CG}$ flash activity greater than $+\mathrm{CG}$ flashes, although the $+\mathrm{CG}$ flash production increased two times if compared to the systems that lasted less than $2 \mathrm{~h}$. As in the Dry period, a higher number of $+\mathrm{CG}$ flashes $\left(0.8-2.2 \mathrm{CG} \mathrm{km}^{-2} \mathrm{~min}^{-1}\right.$ thunderstorm $\left.{ }^{-1}\right)$ were observed from the mature $\left(t_{\text {norm }}=0.5\right)$ to the dissipation $\left(t_{\text {norm }}>0.7\right)$ stages, however the number of $-\mathrm{CG}$ flashes remained higher (2.7-4.3 $\mathrm{CG} \mathrm{km}^{-2} \mathrm{~min}^{-1}$ thunderstorm ${ }^{-1}$ ). During the Transition period thunderstorms longer than 120 min had $+\mathrm{CG}$ flashes frequencies up to $2.1 \mathrm{CG}^{-1} \mathrm{~km}^{-2}$ thunderstorm ${ }^{-1}$. The statistical significance of these results show that $+\mathrm{CG}$ and $-\mathrm{CG}$ flash rate densities are significantly different at $95 \%$ level for most of the thunderstorms life cycle $\left(0.3 \leq t_{\text {norm }} \leq 0.6\right)$ that lived longer than 120 min during the Transition period and thunderstorms with 30-60 min of lifetime during the Wet season. The other lifetime categories of thunderstorms during the Transition and Wet seasons had sporadic $t_{\text {norm }}$ with statistical significance, except the thunderstorms that lived 30-60 and >120 min during the Wet season, which presented significant differences at maturation to dissipation stages.

[40] As pointed before, it has been found a persistent increase in the percentage of $+C G$ flashes during September and October and this outcome could be related to the cloud microphysics of those thunderstorms. To depict this effect, all thunderstorms observed by the weather radar were classified according to their percentage of $+\mathrm{CG}$ flashes observed. For instance, the thunderstorms that had more than $50 \%$ of $+\mathrm{CG}$ flashes over more than $50 \%$ of their lifetime were classified as positive thunderstorms, while the remaining ones were classified as negative thunderstorms. This criteria assures that $+\mathrm{CG}$ flashes occurred during most of all life cycle stages of the systems, and not only during the dissipation stage, when a higher frequency of positive flashes is expected [Lang et al., 2004; Rust et al., 2005]. The results of this classification are presented in Table 2 that summarizes the number of positive and negative thunderstorms for each period and lifetime category. The Dry period had more than $60 \%$ of the thunderstorms classified as positive, up to $90 \%$ of the cases that lasted more than $2 \mathrm{~h}$. During the Transition and Wet periods only $23-38 \%$ of the thunderstorms were positive. These results of Table 2 indicate that the majority of the Dry period thunderstorms were positive, a characteristic that is not found during the other two periods. This in turn should suggest a change in the electrical charge structure inside the thunderclouds of the Dry period.

[41] To inspect any particularities in the thunderstorms' vertical structure that lead to different fractions of positive and negative discharges, we analyze the temporal evolution of $30 \mathrm{dBZ}$ echotops and the vertical integrated liquid (VIL) water content. As pointed by several authors [Rutledge et al., 1992; Williams et al., 1992; Zipser and Lutz, 1994; Petersen et al., 1996, 1999], the $30 \mathrm{dBZ}$ echotop height might be an indication of the lightning activity, while the VIL is related to the production of ice particles that lead to the establishment of the charge transfer.

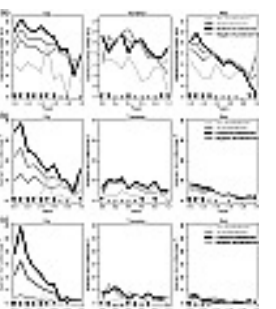

Figure 7. (a) Mean maximum $30 \mathrm{dBZ}$ echotop (cloud height), mean maximum VIL at (b) 2-20 km ("total water"), and (c) 5-20 km of height ("cold water") during positive thunderstorms, negative thunderstorms, thunderstorms in general (positive + negative), and nonthunderstorms normalized lifetime for the Dry, Transition, and Wet periods. The triangles represent the samples that were statistically significant at the $95 \%$ significance level performed for each $t_{\text {norm }}$ comparing the variances between positive and negative thunderstorms (black triangles) and comparing variances between thunderstorms and nonthunderstorms (gray triangles).

[42] Figure 7 shows the mean maximum $30 \mathrm{dBZ}$ echotops and the mean maximum total $(2-20 \mathrm{~km})$ and cold + mixed ( 5 to $20 \mathrm{~km}$ of height $) \mathrm{VIL}$. It can be observed that, 

differences related to the negative ones, while in the Wet period positive thunderstorms were also about $4 \mathrm{~km}$ higher than the negatives at their values of $30 \mathrm{dBZ}$ echotops, but only at their initiation phase $\left(t_{\text {norm }} \leq 0.3\right.$, with statistical significance at 95\%). Nonthunderstorms had maximum $30 \mathrm{dBZ}$ heights around $6 \mathrm{~km}$, characterizing the nonactivation of the ice phase inside these clouds, and consequently the nonoccurrence of CGs. The positive thunderstorms of the Dry period had mean maximum total VIL (Figure 7b) always higher than the negatives, with differences of 12 to $25 \mathrm{kgm}^{-2}$ at the initiation phase ( $t_{\text {norm }}=0.1$ ), decreasing to 4 to $10 \mathrm{kgm}{ }^{-2}$ at the mature phase $\left(t_{\text {norm }}=0.6\right.$ ), and $\sim 2 \mathrm{kgm}^{-2}$ at the dissipation phase $\left(t_{\text {norm }}=0.8\right)$. The cold VIL evolution (Figure $7 \mathrm{c}$ ) of positive and negative thunderstorms followed the total VIL characteristics, with a maximum of $29.8 \mathrm{kgm}^{-2}$ at $t_{\text {norm }}=0.1$ for the positive thunderstorms, decreasing to $7.5 \mathrm{kgm}^{-2}$ at $t_{\text {norm }}=0.6$. The VIL differences between positive and negative thunderstorms were statistically significant at $95 \%$ level during the Dry period from their initiation throughout their maturation $\left(t_{\text {norm }} \leq 0.6\right)$.

[43] These results indicate that for positive thunderstorms the ice phase exerts an important role on the electrification of these clouds, suggesting a more intense behavior of these thunderstorms. However, the Transition and Wet periods did not show significant differences in the mean maximum of these variables, but reinforced the presence of higher values in positive than in negative thunderstorms during practically all phases of the cloud development during the Transition period and during the initiation of the Wet period.

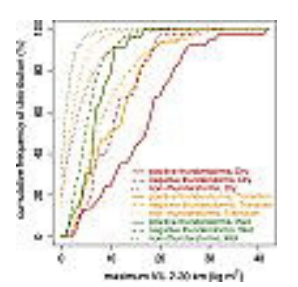

Figure 8. Cumulative frequency distribution of the maximum VIL at 2-20 km (“total water") during positive (solid lines), negative (dashed lines), and nonthunderstorms (dotted lines) of Dry, Transition, and Wet periods.

[44] In order to understand the importance of the maximum values of VIL to the strength of the thunderstorms, Figure 8 presents the cumulative distribution frequency (CDF) of the maximum total VIL (cloud base to cloud top). More than $50 \%$ of the positive thunderstorms during the Dry period had a maximum value of VIL higher than $18 \mathrm{kgm}^{-2}$, while only $\sim 15 \%$ was found for negative thunderstorms in the Dry Period and positive and negative in the Transition period had these values. Moreover, none of the Wet period thunderstorms had VIL higher than $18 \mathrm{kgm}^{-2}$ and lastly more than $50 \%$ of all nonthunderstorms showed values lower than $3.5 \mathrm{kgm}{ }^{-2}$ during all periods.

[45] In summary, as the wet season is established, the maximum thunderstorm cloud top height decreases (Figure 7) as well as the VIL for both types of thunderstorms. Positive thunderstorms during the Dry period were deeper and stronger (higher $30 \mathrm{dBZ}$ echotops and higher VIL) than the negative ones from the same period and all storms from the Transition and Wet periods. In the next subsessions we investigate the environmental features that can influence these cloud systems by focusing on the influence of atmosphere thermodynamics, land cover (vegetation), topography, and finally the impact of the atmospheric pollution that is related to biomass burning.

\subsection{Topography and Vegetation Cover Influences}

Figure 9. Cumulative frequency of occurrence (\%) of the percentage of the precipitating systems' area over each vegetation type (Deforested, Forest, and Others) when first detected by the radar for (a) positive (solid lines) and negative (dashed lines) thunderstorms, and (b) thunderstorms 
(solid lines) and nonthunderstorms (dashed lines).

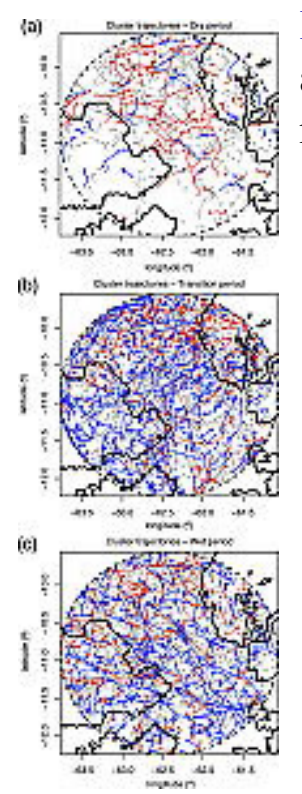

Figure 10. Trajectory of each raining cluster during Dry, Transition, and Wet periods. Positive and negative thunderstorms are represented by red and blue lines, respectively, and the nonthunderstorms are represented by gray lines. Dots indicate where the system was first detected by the radar. Bold black lines delimitate the deforested area (inner region), and the dashed line delineates the radar coverage (150 km of radius).

[46] As presented in sections 4 and 5.1, the \%+CGs during the dry season (September, Figures 3 and 4) is higher over the deforested area of Rondonia. The correlation between the thunderstorms and the land cover of the radar area is summarized at Figures 9 and 10. Figure 9 shows the cumulative frequency distribution of each vegetation type under the raining systems when first detected by the radar $\left(t_{n o r m}=0\right)$, for positive, negative and nonthunderstorms during the Dry, Transition, and Wet periods. The same type of cumulative distribution of occurrence analysis of Figure 9 was performed for all values of $t_{\text {norm }}$ (not shown), but no significant differences were found so here it is presented only the analysis for $t_{\text {norm }}=0$. It can be seen that thunderstorms and nonthunderstorms (Figure $9 \mathrm{~b}$ ) presented just very small differences $(<7 \%)$ in their occurrence/areal coverage under all types of vegetations regardless of the period. The only difference observed is a shift of $10 \%$ more frequent systems (both thunderstorms and nonthunderstorms) at deforested areas than over forested and other types of vegetations during the Dry period compared to the other two periods. For example, half of these clouds (50\%) had more than $70 \%$ of their areal coverage composed by deforested vegetation during the Dry period, while during the Transition and Wet periods only $40 \%$ of the raining systems presented more than $70 \%$ of their areal coverage composed by deforested vegetation.

[47] The Dry season positive and negative thunderstorms (Figure 9a) showed that half of the positive storms had coverage larger than $70 \%$ composed by deforested vegetation, while half of the negative storms presented only $51 \%$ of this type of vegetation. Most of the negative thunderstorms formed under forested areas during the Dry season: $40 \%$ of the negative ones had the majority ( $>51 \%$ ) of forested land under them, against $20 \%$ of the positive ones. During the Transition and Wet seasons, the positive and negative thunderstorms presented similar vegetation coverage under them as in thunderstorms and nonthunderstorms of the same periods (Figure $9 \mathrm{~b}$ ). These results indicate that positive and negative and positive thunderstorms differ in terms of preference of vegetation area under them only during the Dry period, while the thunderstorms and nonthunderstorms systems did not show distinguished differences between them and between periods.

[48] Thereby, to reinforce the preference of positive thunderstorms to form over deforested areas, especially during the Dry period, Figure 10 shows the trajectory of the 
raining clusters during the three periods. It can be seen that the majority of the positive thunderstorms initiated, developed and dissipated over the deforested region during the Dry period, while the negative and nonthunderstorms did not show such preference. During the Transition period, positive thunderstorms tend to form over the deforested areas and forested areas at east, that is lowland regions east of the northwest-southeast high elevated terrain (Figure 1). During the Wet period thunderstorms of both polarities and nonthunderstorms formed in any type of vegetation.

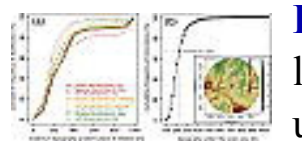

Figure 11. (a) Cumulative frequency of occurrence of the maximum topography under the area of nonthunderstorms (dotted lines), positive (solid lines) and negative (dashed lines) thunderstorms, during the raining clusters initiation, for the Dry, Transition, and Wet periods. (b) Topography under the radar (cross) area as well as its cumulative frequency of occurrence.

[49] Figure 11a shows the cumulative distribution frequency of the maximum topography under the positive, negative and nonthunderstorms, at their place of initiation (section 3.2.1). The maximum topography is then determined by a $5 \mathrm{~km}$ radius area around the position of initiation. It can be observed from Figure $11 \mathrm{a}$ that negative thunderstorms stand out for initiating at higher elevations only during the Dry periods. $32 \%$ of the negative thunderstorms were formed over terrain higher than $400 \mathrm{~m}$, while Dry period positive thunderstorms as well as all thunderstorms of the other periods presented only $\sim 15 \%$ of initiation over terrain $>400 \mathrm{~m}$. The area covered by the radar that has elevations higher than $400 \mathrm{~m}$ is about only 8\%, as shown in Figure 11b, and even then negative Dry period thunderstorms were more frequent over higher terrain. This feature can also be inferred from Figure 10, where most of the negative thunderstorms during the Dry period were first detected by the radar west of the deforested area or around its west boundary, where the higher elevations of the region occur (Figure 1). Figure 11 a also shows that $70 \%$ and $78 \%$ of the Transition, Wet, and Dry periods nonthunderstorms occurred over terrains lower than $220 \mathrm{~m}$ (representing $66 \%$ of the area covered by the radar, Figure $11 \mathrm{~b}$ ).

\subsection{Thunderstorm Environment Thermodynamics}

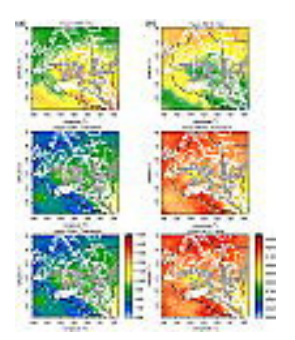

Figure 12. Spatial distribution of the mean (a) cloud base height ( $\mathrm{CBH}$ ) and (b) warm cloud depth (WCD), during the Dry, Transition, and Wet periods. White circle illustrates the radar coverage (150 km radius). White and gray lines delineate the deforested vegetation and topography higher than $250 \mathrm{~m}$, respectively.

[50] Here we investigate the atmospheric thermodynamical variables over the deforested and forested regions within the radar area that are associated to the raining systems detected by the radar that had and did not have cloud-to-ground lightning activity. Figure 12 shows the mean spatial distribution of cloud base heights and warm cloud depths during the Dry, Transition, and Wet periods. The mean Dry period CBH over Rondonia state ranged from 900 to $1500 \mathrm{~m}$, while over the radar coverage it was observed values from 1050 to $1350 \mathrm{~m}$, where the higher $\mathrm{CBH}$ values were located over the deforested area, especially on the west portion of the deforestation near elevations of about $250 \mathrm{~m}$, just south off the radar center. Meanwhile, the mean CBH dropped to $900-1050 \mathrm{~m}$ over the radar area during the Transition period and to 700-950 m during the Wet period as a consequence of the soil moisture availability. As a result, the mean values of WCD over the radar area during the Dry period increased from 3,600 to 3,800 $\mathrm{m}$ and to 3,900-4,200 $\mathrm{m}$ in the Transition and Wet periods.

[51] The above results corroborate with the outcomes found by Fisch et al. [2004] that analyzed the differences between the convective boundary layer over forested and 
deforested areas in Rondonia. Basically it was found a CBH difference of 500-600 m over pasture and forest during the dry season. The source of this difference relays on the energy partition between sensible $(\mathrm{H})$ and latent (LE) heats, where replacing forest by pasture reduced the evapotranspiration and consequently increased the sensible heat $(\mathrm{H})$. During the wet season, the constant precipitation gives the pasture a source of soil moisture, and its evapotranspiration and consequent LE are increased. This fact reduces the $\mathrm{H}$ and LE energy partition difference and no dramatically difference in the PBL height and CBH can be found between forested and deforested areas. By enhancing the sensible heat it is possible to create more intense turbulent transients over deforested areas, thus making the PBL higher over pasture than over forest.

[52] As a consequence, higher $\mathrm{CBH}$ in conjunction with shallower WCD during the Dry period promotes less entrainment of drier environment air inside the warm portion of the developing clouds. Moreover, according to Williams et al. [2005] and Carey and Buffalo [2007], this scenario results in less dilution of cloud buoyancy and cloud water, which in turn promotes a better processing of the convective available potential energy (CAPE). As a result, this energy results in stronger updrafts that favor the availability of more liquid and water vapor for the mixed and cold phases of the cloud. For instance, stronger updrafts (higher cloud tops) and higher maximum mixed/cold VIL were observed in the Dry period for the positive thunderstorms (Figure 8). Therefore, the enhanced differences in the PBL thermodynamics between forest and pasture can explain the higher $\mathrm{CBH}$, shallower WCD, stronger updrafts and higher cold/mixed VIL of the positive thunderstorms, which need the last two ingredients to have graupel and hail charged positively according to several laboratory results [Takahashi, 1978; Saunders et al., 1991; Pereyra et al., 2000; Saunders et al., 2004].

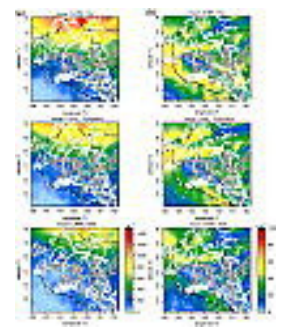

Figure 13. Same as Figure 12, except for (a) CAPE and (b) CINE.

[53] With a relatively drier atmosphere and enhanced sensible heating during the dry season, higher values of CAPE and CINE combined are expected. Figure 13 shows the mean CAPE and CINE over Rondonia during each period of the DRYTOWET campaign. It can be seen that relatively higher mean values of CAPE (up to $800 \mathrm{Jkg}^{-1}$ ) were observed in the Dry period than the Transition (up to $600 \mathrm{Jkg}^{-1}$ ) and Wet (up to $500 \mathrm{Jkg}^{-1}$ ) periods over the radar area. These higher CAPE followed the regional topography, being exactly aligned to the east of the elevated northwest-southeast area (gray lines in Figure 13) during the Dry and Transition periods, while during the Wet period the mean values of CAPE decreased and followed the mean low level moisture transport from northeast Amazon [Silva Dias et al., 2002]. CINE was lower (0-15 $\mathrm{Jkg}^{-1}$ ) at the higher topography region ( $>300 \mathrm{~m}$ ) during all periods, and slightly higher $\left(40-55 \mathrm{Jkg}^{-1}\right)$ upslope of the $\sim 300 \mathrm{~m}$ topography over the north and southeast regions of the radar area during the Dry period. Lower values of CINE over higher landscapes are expected, because they are elevated heat sources, which consequently lower the inhibition of convection. As CAPE is an estimate of the energy for convection and CINE is the correspondent inhibition, we can speculate that during the Dry period, there was more energy for the convection development and inhibition as well. Nonetheless, the combination of these two features can result in an "explosive" convection scenario. However, if this scenario is associated to the previous discussed scenario of higher CBH and consequent lower WCD (Figure 12), the resulting convection can be even more intense since CAPE can be better processed and transferred into stronger updrafts thus higher $L W C$ due to lower entrainment and dilution of buoyancy (updrafts) until the cloud reaches the cold phase. Stronger convection could be inferred by the mean higher echotop (Figure 7a) of the Dry period for both positive and negative thunderstorms, with the first one being more intense (higher echotops). 
Figure 14. Cumulative frequency of distribution at the initiation place (30 min before first appearance on the radar screen) of the (a) maximum $\mathrm{CBH}$, (b) minimum WCD, (c) maximum CAPE, and (d) maximum CINE for DRYTOWET thunderstorms, during the Dry, Wet, and Transition periods.

[54] To individually evaluate the importance of these thermodynamics variables to the positive and negative thunderstorms, and also to the nonthunderstorms for each period, Figure 14 shows the cumulative frequency distributions of the maximum $\mathrm{CBH}$, minimum WCD, maximum CAPE and maximum CINE on a $10 \mathrm{~km}$ radius around the position of initiation of the raining clusters, that is, $30 \mathrm{~min}$ before its appearance in the radar precipitating field, according to their velocity and displacement during the first $30 \mathrm{~min}$ (section 3.2.1). It can be seen on Figure 14a that all Dry period precipitating systems were formed in environments with higher CBH than in the Transition and the Wet periods: $28 \%$ of the maximum CBH values for the Dry period clouds are higher than $1500 \mathrm{~m}$, while only 5\% of the Transition period clouds and the Wet period negative thunderstorms and nonthunderstorms presented values higher than that. Dry period negative thunderstorms had $19 \%$ of occurrence under environments with maximum $\mathrm{CBH}$ greater than $2000 \mathrm{~m}$, against only $\sim 10 \%$ of the positive and nonthunderstorms. This is a reflection of the high occurrence of negative thunderstorms over the elevated terrain $(>300 \mathrm{~m}$ ) immediately west of the deforestation area, as already shown in Figures 10 and 11 , as well as in the mean higher CBH during the Dry period in Figure 12a. Elevated terrain can be considered as an elevated heat source, which in turn elevates the lifting condensation level and therefore $\mathrm{CBH}$.

[55] Associated to the higher CBH in the negative thunderstorms of the Dry period, $15 \%$ of these storms had minimum WCD (Figure $14 \mathrm{~b}$ ) lower than $2500 \mathrm{~m}$, while $6 \%$ of the positive and nonthunderstorms of this period showed minimum WCD lower than that value. Practically, all raining clusters of the Transition and Wet periods initiated over places with minimum WCD higher than $2400 \mathrm{~m}$. The results of negative thunderstorms developing in environments with higher minimum WCD and maximum CBH do not agree with those found by Carey and Buffalo [2007], who associated the presence of shallower WCD to the development of positive thunderstorm. However, our negative thunderstorms were mainly formed over elevated terrain, as discussed above, which implies elevated CBH and therefore shallower WCD. Furthermore, Carey and Buffalo [2007] studied severe thunderstorms which are in general long-lived storms (lifetime greater than $2 \mathrm{~h}$ ) and dynamically distinct from the tropical thunderstorms here analyzed. In addition, only 9 positive thunderstorms and 1 negative thunderstorm lived longer than $2 \mathrm{~h}$ (maximum of $3.5 \mathrm{~h}$ ) during the Dry period (Table 2).

[56] In Figure 14c, it can be seen that positive thunderstorms from the three analyzed periods developed in environments with higher CAPE than the negative and nonthunderstorms, with the Wet period presenting almost no differences between positive and negative thunderstorms. Actually, negative thunderstorms had very similar distributions of CAPE for all the periods, and the Wet period nonthunderstorms were developed in environments with the lower values of CAPE. On the other hand, $50 \%$ of the Dry period positive thunderstorms occurred over regions with maximum CAPE higher than $1000 \mathrm{Jkg}^{-1}$ against $40 \%$ and only $24 \%$ of the Transition and Wet period positive thunderstorms, respectively.

[57] Maximum CINE cumulative frequency distributions (Figure 14d) showed that the Dry period positive and negative thunderstorms had $46 \%$ and $29 \%$, respectively, of its values greater than $100 \mathrm{Jkg}^{-1}$, while only $5 \%$ or less of Dry period nonthunderstorms and all Transition and Wet periods raining clusters showed maximum CINE higher than $100 \mathrm{Jkg}^{-1}$. Mild differences between thunderstorms and nonthunderstorms of the Transition and Wet can be inferred from CINE.

[58] In summary, the analysis of the environmental thermodynamic variables on the place of initiation the precipitating systems reveled that positive thunderstorms during the Dry period were initiated in environments with high CBH, low WCD, higher CAPE and higher CINE. Large values of CAPE and CINE can produce an "explosive" convection scenario with stronger updrafts and higher availability of LWC in the mixed phase of the clouds, which cloud likely explain the anomalous 

and CINE, which in turn could decrease the potentiality for developing higher LWC at the mixed phase region of the thunderstorm.

\subsection{The Biomass Burning Pollution}

Figure 15. Temporal evolution of total aerosol concentration at Fazenda Nossa Senhora, Rondonia. The Dry, Transition, and Wet periods are indicated.

[59] Last it is important to check whether pollution can contribute into the enhancement of $+\mathrm{CG}$ activity as observed in other regions of the globe [Lyons et al., 1998; Murray et al., 2000; Smith et al., 2003; Fernandes et al., 2006]. Figure 15 shows the temporal evolution of total aerosol concentration $\left(N_{\text {total }}\right)$ from each 10 min interval accumulation of DMPS measured at surface at the Fazenda Nossa Senhora. During the Dry period, $N_{\text {total }}$ is higher than the other two periods during almost $50 \%$ of the time, reaching values higher than $5 \times 10^{4} \mathrm{~cm}^{-3}$ in 22 September 2002. The sudden $N_{\text {total }}$ decrease on 8 October 2002 is associated to the passage of a large MCS whose precipitation scavenged the atmosphere. This episode established the onset of the transition period that promoted the regularity of the precipitation that in turn diminished the number of fire spots all over Rondonia state [Silva Dias et al., 2005]. Thereby, the mean $N_{\text {total }}$ for the Dry period was $12,190 \mathrm{~cm}^{-3}$, against $7,175 \mathrm{~cm}^{-3}$ and $4,103 \mathrm{~cm}^{-3}$ for the Transition and Wet periods, respectively.

[60] The mean $N_{\text {total }}$ during for positive, negative, thunderstorms and nonthunderstorms is presented in Table 3 . We can see that Dry period positive thunderstorms have a slightly higher total concentration of aerosols $\left(1.60 \times 10^{4} \mathrm{~cm}^{-3}\right)$ than the other categories. The same feature is observed during the Wet period, but not during the Transition. These differences were statistically significant at $95 \%$ level only during the Wet period. In the Transition season, positive and negative thunderstorms do not present significant differences in $N_{\text {total }}$, but thunderstorms as a whole and nonthunderstorms differ in by mean $N_{\text {total }}$, as well as in the Wet period.

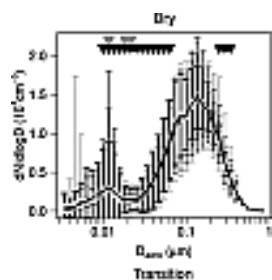

Figure 16. Mean aerosol size distribution (and respective error bars) measured by the DMPS at Fazenda Nossa Senhora during positive, negative, thunderstorms, and nonthunderstorms during the Dry, Transition, and Wet periods. The triangles represent the samples that were statistically significant at the $95 \%$ significance level performed for each $t_{\text {norm }}$ comparing positive versus negative thunderstorms (black triangles) and comparing thunderstorms versus nonthunderstorms (gray triangles) within the same period.

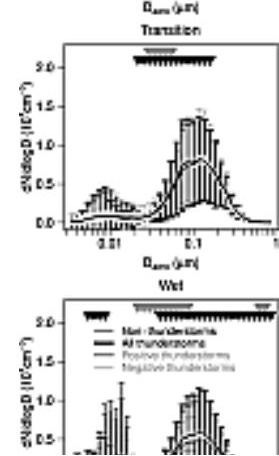


[61] Figure 16 shows the mean aerosol size distribution measured by the DMPS at Fazenda Nossa Senhora during positive, negative, thunderstorms and nonthunderstorms during the Dry, Transition, and Wet periods, as described in section 3.2.3. It can be noted that the aerosol distribution for diameters $\left(D_{\text {aero }}\right)$ greater than $0.03 \mu \mathrm{m}$ have similar spectrums for all positive and negative thunderstorms and nonthunderstorms during the Dry period, with a peak of $\sim 15,000 \mathrm{~cm}^{-3}$ at $D_{\text {aerosol }}=0.2 \mu \mathrm{m}$. The nonthunderstorms for the Dry period had relatively lower aerosol concentrations than the thunderstorms for $D_{\text {aerosol }}<0.3 \mu \mathrm{m}$. Yet during the dry period, negative thunderstorms had lower concentrations varying from 300 to $1,200 \mathrm{~cm}^{-3}$ for $D_{\text {aerosol }}<0.02 \mu \mathrm{m}$. The Transition period showed minor differences between negative and positive thunderstorms, even when the mean aerosol distribution during positive thunderstorms was only $630 \mathrm{~cm}^{-3}$ higher than the negative ones for diameters between 0.08 and $0.14 \mu \mathrm{m}$. However, the Wet period demonstrated significant differences on the aerosol size distribution for positive, negative and nonthunderstorms, especially for aerosols in the diameter range of $0.07-0.4 \mu \mathrm{m}$. Moreover, positive thunderstorms presented higher concentrations $\left(300-1000 \mathrm{~cm}^{-3}\right)$ than the negative ones, and even higher (500-2150 $\mathrm{cm}^{-3}$ ) when compared to the nonthunderstorms. On a statistical analysis of the significance of these differences (as described in section 3.3 and highlighted in Figure 16) it can be seen that thunderstorms and nonthunderstorms are the categories that differ the most, where almost all size bins of DMPS presented significant different $N_{\text {total }}$ during the Dry and Wet seasons. In the Dry and Transition periods, positive and negative thunderstorms do not differ in terms of size distributions, but the significant differences increased in the Wet period.

[62] The mean mass diameter (diameter pondered by its total concentration, $\left.\overline{D_{m}}\right)$ of positive thunderstorms were relatively smaller $(0.128 \mu \mathrm{m})$ than the negative ones $(0.137 \mu \mathrm{m})$, as well as the overall thunderstorms $(0.131 \mu \mathrm{m})$ in comparison with the nonthunderstorms $(0.142 \mu \mathrm{m})$ during the Dry period. The Transition period however presented a slightly larger $\overline{D_{m}}$ for positive thunderstorms $(0.108 \mu \mathrm{m})$ than the negative ones $(0.101 \mu \mathrm{m})$, and also the thunderstorms $(0.104 \mu \mathrm{m})$ compared to the nonthunderstorms $(0.0967 \mu \mathrm{m})$. During the Wet period, the mean mass diameter was relatively similar for all categories of storms $(\sim 0.121 \mu \mathrm{m})$. The differences in $\overline{D_{m}}$ between positive and negative thunderstorms, as well as between thunderstorms and nonthunderstorms, were statistically significant at $95 \%$.

[63] These results of Table 3 and Figure 16 suggest that the environment where clouds developed during the Dry and Transition period do not differ in the total concentration of the aerosol, but do differ in $\overline{D_{m}}$. On the other hand, the environment of the Wet period do differ in both $N_{\text {total }}$ and $\overline{D_{m}}$ but do differ in the aerosol total concentration as well as on the concentration for each bin size measured by the DMPS (Figure 16). Therefore, the results shown above do not give concrete support for the hypothesis of increased production of +CGs by increased ingesting of biomass burning [Lyons et al., 1998; Murray et al., 2000; Williams et al., 2002; Smith et al., 2003; Fernandes et al., 2006]. Nevertheless, the Wet period showed a significant difference in the size distribution of the positive, negative, thunderstorms and nonthunderstorms. This substantial difference can inspire a possible aerosol effect on cloud development in relatively clean environments like the Wet period, while during the Dry period the environment was saturated with aerosols.

\section{Summary and Discussions}

[64] The climatological analysis of CG, presented in section 4, showed an annual variability associated to the wet season establishment. The number of CGs increases from August to November, associated to the gradual increase of water vapor availability for developing convective systems. The number of CGs is high until April, when the dry season is established and large-scale patterns inhibit convection in Rondonia.

[65] September presents a significant signature among the other months, i.e., higher concentration of + CGs lightning that it is aligned with the deforested areas of 

higher and WCD was shallower, and clouds were deeper (stronger updrafts) and had more mixed and cold VIL, resulting in stronger thunderstorms observed during the experiment. Fewer negative thunderstorms occurred during the Dry period and they initiated over all vegetation types, as well as the nonthunderstorms that also developed over both pasture and forest. The negative thunderstorms also presented high $\mathrm{CBH}$ and shallow WCD, even higher and shallower than the positive ones, but this was related to the elevated terrain where they were formed. Elevated terrain can be considered as an elevated heat source, which in turn elevates the lifting condensation level and therefore $\mathrm{CBH}$ and shallows the WCD. But this same elevated terrain also decreases CAPE and CINE, which in turn could decrease the potentiality for developing higher LWC at the mixed phase region of the thunderstorm.

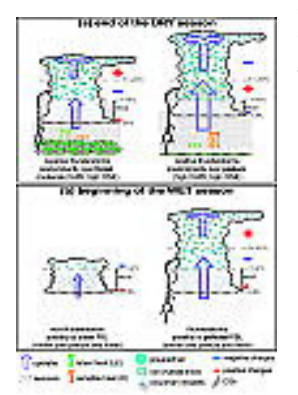

Figure 17. Conceptual illustration of cloud electrification during (a) the end of the dry season and (b) during the beginning of the wet season in the southwestern Amazon. For detail, please refer to the text.

[66] Since the positive thunderstorm generation was preferentially over deforested areas during the Dry period, the WCD depth hypothesis of Carey and Buffalo [2007] could be the mechanism for intensifying thunderstorms, and the "big picture" of cloud electrification during this period is conceptually illustrated in Figure 17a. The Amazon deforestation modifies the energy partition between sensible and latent heat, since the forest substitution by pasture decreases the evapotranspiration particularly during the dry season. The increased sensible heat generates turbulent transients over the deforested, creating a higher PBL. Thereby, the PBL mixture layer over the forest is shallower than over the pasture, generating density and pressure gradients that respond with local circulations during the afternoon, as a pasture-forest breeze [Baidya Roy and Avissar, 2002]. As the top of the PBL is higher over the pasture, the CBH of clouds generated in this area (as a result of the pasture-forest breeze convergence) is also higher, which implies in shallower WCD and less dilution of cloud water and buoyancy during their development. This environment allows CAPE to be better processed though intensifying the updrafts, suppressing warm precipitation and increasing mixed phase liquid water content. More liquid water in the mixed phase can allow graupel to be positively charged in collisions with small ice particles for a wider range of temperatures inside the cloud, generating an inverted polarity thunderstorm that leads to the predominance of $+\mathrm{CGs}$.

[67] The atmospheric loading of biomass burning was different during the Dry, Transition, and Wet periods. During the Dry and Transition periods, positive, negative, thunderstorms and nonthunderstorms did not show significant differences in terms of the aerosol variables analyzed here. However, during the Wet period (when there is enough water vapor and the atmosphere is mostly unstable) both negative and positive storms occurred during periods of higher aerosol concentration and differentiated size distributions, suggesting a possible aerosol effect. During the wet season, when the atmosphere has relatively higher concentrations of aerosols, clouds would have their warm precipitation suppressed, which in turn would lead to an enhanced mixed and ice regions enabling electrical charge transfer during collisions of ice particles, and thereby their evolution to thunderstorms. This conceptual model is illustrated in Figure $17 \mathrm{~b}$.

[68] In this line of thought, Reutter et al. [2009] formulated three regimes of CCN activation and droplet formation: (1) an aerosol-limited regime, characterized by high ratios between the updraft velocity $(w)$ and the number of $\operatorname{CCN}\left(N_{C C N}\right)\left(w / N_{C C N}>\approx 10^{-3} \mathrm{~m} \mathrm{~s}^{-1} \mathrm{~cm}^{3}\right)$, high maximum supersaturation $\left(S_{\text {max }}\right)$, and therefore high activated 
$\left.\mathrm{cm}^{3}\right), S_{\max }(<\approx 0.2 \%)$ and activated droplets $\left(N_{\text {droplets }} / N_{C C N^{*}}<\approx 20 \%\right)$; and (3) and aerosol- and updraft-sensitive regime (transitional regime), characterized by intermediate parameter values. Therefore, in regime $1 N_{\text {droplets }}$ is directly proportional to $N_{C C N}$ and practically independent of $w$, while in regime $2 N_{d r o p l e t s}$ is directly proportional to $w$ and practically independent of $N_{C C N^{*}}$, and in regime $3 N_{\text {droplets }}$ depends nonlinearly on both $w$ and $N_{C C N}$ [Reutter et al., 2009]. Translating these regimes to what we have observed in the DRYTOWET field campaign, the Dry period was overwhelmed with high and extremely high concentrations of aerosols, suggesting that the activation of $\mathrm{CCN}$ and cloud droplets formation could typically occur in the updraft-limited or transitional regimes, as well as probably the Transition period. In this case, the number of cloud droplets would highly depend on the updraft velocity at the cloud base. Higher updrafts could be acquired by higher values of CAPE, and the positive thunderstorms presented higher values of CAPE during both Dry and Transition periods (especially during the Dry period, Figure 14). The positive thunderstorms of the Dry period also presented higher values of CINE, which combined with high CAPE could develop "explosive" convection and high updraft velocities. This fact alone ("explosive" convection) would ingest higher LWC in the mixed phase, which also could be increased by the higher number of activated cloud droplets (which are smaller in size), supporting the hypothesis of positive charging of graupel at high values of LWC [Takahashi, 1978; Saunders and Peck, 1998; Pereyra et al., 2000; Saunders et al., 2004] and also smaller supercooled droplets [Pereyra et al., 2000]. However, numerical simulations have also pointed the fact that smaller supercooled droplets can decrease the rimming rate of ice particles [Carrio et al., 2010; Ward et al., 2010], and thus decrease the number and size of ice in the cloud and this have a great potential to decrease the electrification and lightning generation of the cloud.

[69] On the other hand, the atmospheric pollution in the Wet period is drastically reduced with the establishment of the rain season, suggesting that this period might be representative of the aerosol-limited regime of Reutter et al. [2009]. In this case, the number of nucleated droplets would be directly proportional to the number of aerosol particles and scarcely influenced by the updraft velocity. In terms of the thermodynamics of the environment during this period, little or no difference was observed in values of CAPE, $\mathrm{CBH}, \mathrm{WCD}$ and CINE between positive and negative thunderstorms, but significant differences were found for CAPE and CINE between thunderstorms and nonthunderstorms (Figure 14). This reflect the well known fact that thunderstorms are developed in higher instable environments, does not give any information on possible in the polarity of CGs. Therefore, as in a possible aerosol-limited regime, slightly higher concentrations of aerosols could provide larger LWC in the mixed phase, which will increase the ice content of the cloud and possibly charge graupel positively (Figure 16 and Table 3 ). In this case, the size of the activated droplets should be not too small as in the Dry period, and the possibility of decreasing the ice rimming efficiency and ice content should not be an issue.

[70] It is important to state that the suggestions presented above are not observed facts, they are just hypotheses based on plausible physical mechanisms. A more confident evaluation of suggested causalities requires in situ microphysical observations and advanced bin-microphysical and electrical cloud modeling to investigate all links of the various complex hypothesis chains invoked herein. In summary, the radar and lightning observations can indirectly address only the dynamical, microphysical and electrical aspects of these hypotheses. Even then, the suggested causalities are consistent with the invoked hypotheses.

\section{Conclusions}

[71] The objective of this study was to investigate the physical processes involved in the development of thunderstorms over southwestern Amazon (Rondonia) in addition to understand what could explain the observed cloud-to-ground lightning variability in this area. This variability consisted in the increase of the atmospheric discharge occurrences during the transition between the dry and wet seasons and the high percentage of + CGs in the end of the dry season. Besides these facts, the southwestern Amazon experienced a large variety of environmental factors, such as the gradually increase in atmospheric moisture and extremely high pollution due to biomass burning. This region also exhibits intense deforestation and replacement of native vegetation by continuous bands of pasture, which directly affects cloud development by differential surface energy partition.

[72] Our concluding remarks are that thunderstorms electrification in Rondonia is governed by a combination of effects, where large-scale, mesoscale, microphysics, 
landscape and topography play together and can contribute in some degree to thunderstorm development. In the end of the dry season the control conditions imposed by the large-scale and local environmental thermodynamics favored the development of positive thunderstorms over deforested, while during the wet season thunderstorm development (of any polarity) might be regulated by the CCN concentration of the atmosphere. It is important to note that the presented results are consistent with the proposed hypotheses which might suggest a causality relationship; however, with the available data these relationships remain empirical and consistent with what was previously observed in the literature.

\section{Acknowledgments}

[73] This work was funded by the Fundação de Amparo à Pesquisa do Estado de São Paulo (FAPESP) under grant 04/09049-3, and is part of a Ph.D. dissertation. It was also partially funded by the Coordenação de Aperfeiçoamento de Pessoal de Nível Superior (CAPES), PROEX-CAPES, and the Environmental and Climate Program of the European Commission (contract EVK2-CT-2001-00110 SMOCC). We thank Paulo Artaxo (Departamento de Física Aplicada, Universidade de São Paulo) for the aerosol data and his assistance in processing it, and Richard Blakeslee (Marshall Space Flight Center, NASA) and Jeffrey Bailey (University of Alabama in Huntsville) for the RLDN data and the valuable discussions on this topic. We also thank the anonymous reviewers, who richly contributed to the improvement of this manuscript.

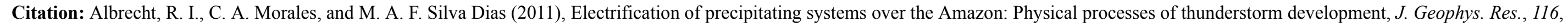
D08209, doi:10.1029/2010JD014756.

Copyright 2011 by the American Geophysical Union. 